\title{
Metilfenidato e Aprimoramento Cognitivo Farmacológico: representações sociais de universitários'
}

\section{Methylphenidate and Pharmacological Cognitive Enhancement: social representations of university students}

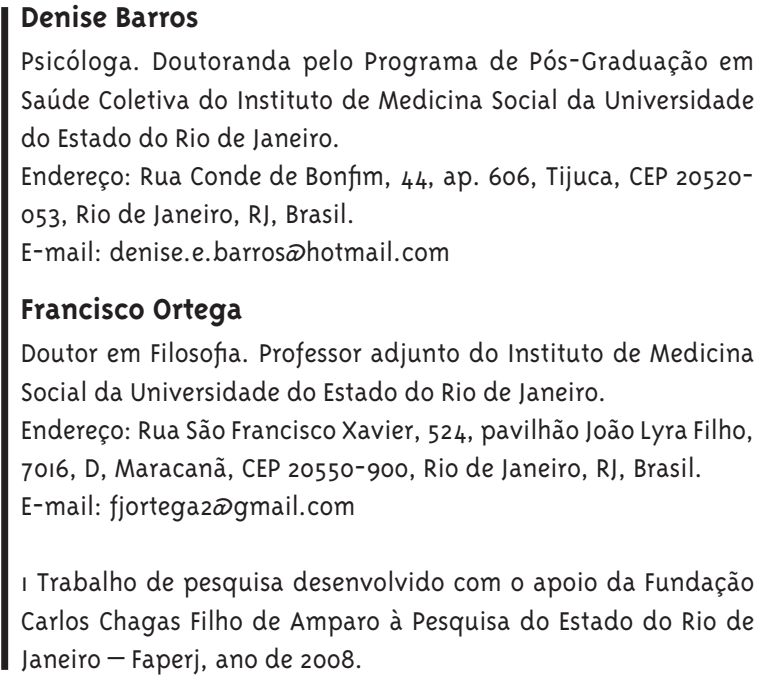

\section{Francisco Ortega}

Doutor em Filosofia. Professor adjunto do Instituto de Medicina Social da Universidade do Estado do Rio de Janeiro.

Endereço: Rua São Francisco Xavier, 524, pavilhão João Lyra Filho, 7016, D, Maracanã, CEP 20550-900, Rio de Janeiro, RJ, Brasil.

E-mail: fjortega2œgmail.com

I Trabalho de pesquisa desenvolvido com o apoio da Fundação Carlos Chagas Filho de Amparo à Pesquisa do Estado do Rio de Janeiro-Faperj, ano de 2008.

\section{Resumo}

0 artigo tem por objetivo apresentar o resultado da investigação das representações sociais de 20 estudantes universitários sobre o uso de metilfenidato para aprimorar o desempenho cognitivo em pessoas saudáveis. Nesta pesquisa qualitativa, de cunho exploratório, 20 universitários entre 18 e 25 anos, oriundos de cursos das áreas de saúde e humanas, foram distribuídos em três grupos focais para debater sobre o Aprimoramento Cognitivo Farmacológico. A análise dos dados revelou que entre esses estudantes houve uma maior tolerância aos métodos que alteram a neurobiologia a favor do ideal social de melhoria da performance das pessoas. Contudo, os entrevistados expressaram grande preocupação com a possibilidade de este procedimento vir a intensificar injustiças e desigualdades entre as pessoas, principalmente nas sociedades em que já existem significativas diferenças sociais. Assim, apesar de o tema ser pouco estudado no Brasil, a análise dos dados da presente investigação sugere que o Aprimoramento Cognitivo Farmacológico é um assunto atual e relevante. Não apenas por esta prática estar relacionada à construção e manutenção da subjetividade dos indivíduos em uma sociedade que prioriza a melhoria da performance cognitiva, mas também pelo risco de esta interferir em questões de igualdade e justiça social.

Palavras-chave: Ciência, Tecnologia e Sociedade; Aprimoramento Biomédico; Metilfenidato; Cognição; Subjetividade; Grupos Focais. 


\section{Abstract}

The article aims to present the outcome of the investigation of social representations of 20 university students on the use of methylphenidate to improve cognitive performance in healthy people. In this qualitative and exploratory research, 20 university students between 18 and 25 years from health and humanities courses were divided into 3 focus groups to discuss about Pharmacological Cognitive Enhancement. Data analysis revealed that these students had greater tolerance to methods that alter neurobiology in favor of the social ideal of improving the performance of people. However, respondents expressed great concern about this procedure intensifying injustices and inequalities between people, especially in societies where there are already significant social differences. Thus, although the subject is little studied in Brazil, the analysis of data from this research suggests that Pharmacological Cognitive Enhancement is an important and relevant topic. Not only because this practice is related to construction and maintenance of individuals' subjectivity in a society that prioritizes the improvement in cognitive performance, but also because of the risk that this practice interferes in matters of social justice and equality.

Keywords: Science, Technology and Society; Biomedical Enhancement; Methylphenidate; Cognition; Subjectivity; Focus Groups.

\section{Introdução}

Em 2009, as revistas Época, IstoÉ, Scientific American Brasil, Superinteressante e o jornal $O$ Globo trouxeram reportagens sobre pessoas saudáveis que usam remédios para melhorar o funcionamento do cérebro e aprimorar o desempenho cognitivo. 0 tema ganhou algum destaque na mídia brasileira depois de dezembro de 2008, mês em que foi publicado um artigo manifesto na Nature com o título "Towards responsible use of cognitive-enhancing drugs by the healthy" (Greely e col., 2008). Os autores - Henry Greely, Barbara Sahakian, John Harris, Ronald C. Kessler, Michael Gazzaniga, Philip Campbell e Martha J. Farah - defenderam essa aplicação dos recursos médicos e sugeriram estratégias para ajudar a sociedade a aceitar seus benefícios. Entre suas propostas constavam a realização de pesquisas rigorosas e o estabelecimento de regulamentações mais evoluídas, como por exemplo a prescrição das drogas apenas por profissionais capacitados como forma de garantir a segurança do uso e impedir o abuso dos medicamentos. Segundo os autores, a prática teria muito a oferecer e, por esse motivo, a administração dos riscos para promover o acesso de todos ao neuroenhancement seria uma questão de "responsabilidade social".

No Brasil, ainda não existe uma palavra ou expressão estabelecida para nomear essa prática. “Uso instrumental de remédios", "drogas para turbinar o cérebro", "neurologia cosmética”, “doping cerebral" e "drogas de inteligência" foram alguns dos termos utilizados pela mídia para descrever o que no presente trabalho é chamado de "aprimoramento cognitivo farmacológico" ou "neuroaprimoramento farmacológico".

A novidade apresentada no artigo da Nature não está na defesa do aperfeiçoamento, pois este sempre existiu de diversas formas na sociedade. Tratamentos estéticos, treinamentos físicos e inovações nas técnicas de ensino/aprendizagem são alguns exemplos de busca por "melhoramento". A novidade da proposta está na possibilidade de usar remédios e outras intervenções biotecnológicas para modificar o processo cerebral com o objetivo de aprimorar memória, humor e atenção em pessoas saudáveis. 
A discussão sobre o assunto é bastante intensa no Canadá, nos Estados Unidos e na Inglaterra (Greely e col., 2008; Butcher, 2003; Bush, 2006; Caplan, 2003; Caplan e Elliott, 2004; Chatterjee, 2004; Chau, 2007; Dees, 2004; Elliott, 2003; Farah e col., 2004; Fenton, 2009; Racine e Forlini, 2008; Hall, 2004; Hyman, 2006; Mauron, 2003; Maguire e Mcgee, 1999; NIDA, 2005; Kass, 2003; Sahakian e Morein-Zamir, 2007; Sententia, 2004; Singh e Rose, 2006; Turner e Sahakian, 2006; Wolpe, 2002). Muitos desses debates são motivados pelo aumento no número de estudantes que usam psicoestimulantes para melhorar o rendimento acadêmico tornando essa questão um sério problema de saúde pública nos países citados (NIDA, 2005).

De acordo com enquete realizada pela revista $\mathrm{Na}$ ture (Maher, 2008) e alguns estudos epidemiológicos (Hall e col., 2005; Low e Gendaszek, 2002; White e col., 2006; Teter e col., 2005; Teter e col., 2006), um dos medicamentos mais utilizados para esse fim é o cloridrato de metilfenidato, um estimulante do sistema nervoso central que apresenta estrutura semelhante à anfetamina. No Brasil, esse fármaco é mais conhecido pelos nomes comerciais Ritalina ${ }^{\circledR}$ (Novartis) e Concerta ${ }^{\circledR}$ (Janssen-Cilag). Embora sua ação ainda não esteja clara (Diller, 1996; Szobot e col., 2001), o remédio aumenta o desempenho de funções executivas que auxiliam a realização de tarefas cognitivas, além de diminuir a fadiga (Elliott e col., 1997; Mehta e col., 2002; Solanto, 1998; The MTA Cooperative Group, 1999). Esse medicamento é usualmente indicado para o tratamento do Transtorno do Déficit de Atenção e Hiperatividade (TDAH) e para a narcolepsia, um raro transtorno do sono (Novartis Biociências SA, 2007).

O uso desse fármaco é autorizado legalmente apenas para tratar pessoas com transtornos e doenças. Isso ocorre porque o metilfenidato está incluído na Convenção de Substâncias Psicotrópicas de 1971 da ONU (1971). De acordo com esse compromisso, também assumido pelo Brasil, esse medicamento precisa de um controle especial, pois apresenta risco de abuso e dependência.

Apesar da restrição citada, são conhecidos três usos "não médicos" desse remédio: o recreativo, para aumentar o tempo de vigília e disposição durante o lazer; o estético, para auxiliar o emagrecimento; e o aprimoramento cognitivo, para melhorar o desempenho cognitivo profissional e acadêmico (NIDA, 2005). Este último uso, privilegiado no presente artigo, é possibilitado pelo fato de o medicamento proporcionar o aumento na capacidade de concentração, atenção e estado de alerta também em pessoas saudáveis (Diller, 1996).

$\mathrm{Na}$ internet brasileira, localizamos fóruns de discussão sobre o uso do metilfenidato para melhorar o rendimento nos estudos. Entre eles temos: Fórum Darkside; Fórum hardMOB; GUJ; Portal do Vale Tudo; Yahoo! Respostas.

Realizamos uma pesquisa sistemática durante o período de 1997 a 2008 na revista Veja e nos jornais Folha de S.Paulo e $O$ Globo, onde encontramos apenas seis matérias sobre o assunto. Já em 2009, em busca não sistemática, identificamos cinco textos sobre neuroaprimoramento na mídia impressa brasileira. Para complementar o estudo, investigamos também de forma sistemática as revistas científicas indexadas na base Scielo entre 1997 e 2008 e não localizamos nenhum artigo sobre neuroaprimoramento farmacológico com metilfenidato. Dessa forma, mesmo havendo indicações de que a prática é realizada no Brasil, os estudos sobre o tema têm origem em outros países e tratam de suas respectivas realidades.

Racine e Forlini (2008) analisaram artigos produzidos sobre o assunto em Saúde Pública, Bioética, Neuroética e mídia impressa. Como esses autores perceberam que não existe um consenso na aceitação da prática, eles sugeriram a realização de pesquisas para identificar o que estudantes, cidadãos leigos, profissionais de saúde e autoridades em Saúde Pública pensam sobre o tema. Somente tal investigação forneceria informações para uma melhor compreensão das implicações sociopolíticas aí envolvidas.

Seguindo tal sugestão, o artigo tem a proposta de apresentar e discutir os resultados de três grupos focais realizados com o total de 20 universitários. Os integrantes dos grupos debateram sobre o uso de metilfenidato por estudantes para melhorar o rendimento acadêmico. 


\section{Metododologia}

O presente estudo, de cunho exploratório, trata das representações sociais que 20 universitários apresentaram sobre o uso do metilfenidato para melhorar o desempenho acadêmico. Na aplicação dos grupos focais, foram levantados conhecimentos sobre os aspectos gerais do aprimoramento cognitivo farmacológico; as preocupações éticas, sociais e legais relacionadas a essa prática; os aspectos sociais e cuidados com a saúde envolvidos nesse comportamento; e o entendimento e percepção dos participantes sobre a mídia como fonte de informação acerca dessa atividade.

Os entrevistados foram recrutados por meio de convites orais feitos por integrantes da equipe de pesquisa. Os dois critérios para participar da investigação foram: ser universitário (qualquer curso e faculdade) e ter idade entre 18 e 25 anos.

A coleta de dados foi realizada usando dois instrumentos. O primeiro foi um questionário composto por perguntas fechadas e abertas para identificar idade, sexo e ocupação dos entrevistados; se eles próprios eram usuários ou conheciam usuários do metilfenidato para usos médico e "não médico"; se tinham informações sobre o tema e se gostariam de conhecer mais sobre o assunto. Esses dados ajudaram a compor um perfil dos participantes da pesquisa além de revelar quantos tinham algum conhecimento anterior sobre o tema.

Após o preenchimento do questionário individual, os entrevistados iniciavam sua participação no grupo focal. Foram realizados três grupos sendo o primeiro com oito, o segundo com sete e o terceiro com cinco integrantes, somando o total de 20 entrevistados.

O grupo focal é um método de pesquisa qualitativa que favorece o debate entre os entrevistados sobre um tópico sugerido pelo pesquisador. 0 assunto pode ser conhecido ou desconhecido dos participantes, pois a riqueza do método está em explorar a tendência humana de formar e remodelar opiniões e atitudes durante a interação com outros indivíduos. Por esse motivo, é importante que os participantes do grupo focal apresentem certas características em comum (associadas ao tema estudado) para facilitar as discussões. Contudo, não é necessário que o grupo seja totalmente homogêneo, pois a existência de algumas diferenças entre os entrevistados enriquece o debate.

Como nessa técnica é comum o surgimento de insights, mudanças de opinião ou ainda a construção de argumentações mais complexas para o julgamento inicial, a interpretação das falas não pode ser feita de sentença a sentença de forma isolada. As afirmações tendem a ser contra-argumentações ou complementos a ideias anteriormente expressas. É no encadeamento das opiniões que as representações sociais surgem e ganham sentido.

Essas características tornam o método bastante eficiente na etapa de levantamento de dados, pois um número pequeno de grupos pode gerar uma grande quantidade de ideias sobre as categorias do estudo desejado (Carlini-Cotrim, 1996; Krueger, 1988; Minayo, 1992; Morgan, 1997). Contudo, devido à composição intencional e de conveniência da amostra, os resultados não podem ser generalizados para toda a população investigada (Gondim, 2002).

Para favorecer o debate nos três grupos focais, foram apresentados três artigos sobre o tema que saíram na mídia brasileira ${ }^{2}$. A leitura prévia dos textos foi usada como estratégia para fornecer informações sobre o assunto desconhecido para a grande maioria dos entrevistados (Morgan, 1997).

O material coletado a partir dos grupos focais foi analisado com a finalidade de identificar as representações sociais que os universitários apresentam sobre o uso "não médico" do metilfenidato para melhorar o rendimento acadêmico. Para isso, os encontros foram transcritos, analisados e depois categorizados de acordo com o "Guia de Codificação" utilizando o software NVivo. As categorias desse guia foram elaboradas de acordo com as principais ideias discutidas sobre o tema nos artigos estrangei-

2 GARCIA, R. Cientista usa drogas para "turbinar" desempenho. Folha de São Paulo, São Paulo, 11 abr. 20o8. Disponível em: <http://www1. folha.uol.com.br/folha/ciencia/ult306u391158.shtml>. Acesso em: 23 maio 2008.

HIRSCHLER, B. Remédios para melhorar atividade mental geram debates. O Globo Online, Rio de Janeiro, o8 nov. 2007 . Disponível em: <http://oglobo.globo.com/mundo/mat/2007/11/o8/327083411.asp>. Acesso em: 23 maio 2008.

CASTRO, R. Motivo e pretexto. Folha de São Paulo, São Paulo, 14 abr. 20o8. Disponível em <http://www1.folha.uol.com.br/fsp/opiniao/ fz1404200805.htm>. Acesso em: 23 maio 2008. 
ros (científicos e populares). Sua função foi nortear, sem limitar, a compreensão dos encadeamentos de representações expressas pelos grupos.

Antes de assinarem o "Termo de Consentimento Livre e Esclarecido", os indivíduos foram informados quanto aos objetivos da pesquisa, respeitando-se a recusa daqueles que decidiram não participar, em qualquer das etapas da investigação. A pesquisa foi elaborada segundo os princípios éticos da Declaração de Helsinki, como consta em sua aprovação pelo Comitê de Ética em Pesquisa do Instituto de Medicina Social da UERJ no dia 9 de abril de 2008.

\section{Resultados}

As respostas ao questionário mostraram que dos 20 entrevistados, todos inscritos em cursos das áreas de saúde ou humanas, sete eram homens e 13 mulheres. A maioria dos integrantes não era assinante de revista ou jornal, mas quase todos apresentaram interesse em ler artigos que divulguem informações científicas. Na época da pesquisa, todos afirmaram nunca ter recebido prescrição de Ritalina ${ }^{\circledR}$ como também nunca ter feito uso "não médico" desse fármaco. Um dos participantes relatou saber de alguém com prescrição para usar esse medicamento enquanto dois confirmaram o conhecimento de pessoas que haviam feito uso "não médico" da Ritalina ${ }^{\circledR}$. Apenas dois integrantes haviam tido contato com o tema antes da pesquisa. Quase todos os participantes demonstraram interesse em conhecer mais sobre o assunto.

O resultado dos grupos focais revelou que algumas categorias do "Guia de Codificação" foram significativamente mais citadas e discutidas do que outras indicando sua maior representatividade para os estudantes entrevistados.

No Gráfico 1, é possível acompanhar a quantidade de citações referentes a cada tópico em cada um dos três grupos. Cada grupo está representado por uma cor e cada categoria está representada em uma coluna. Dentro dessas colunas, existem números que expressam os valores absolutos de citações feitas por aquele grupo. O número total de citações de uma categoria pode ser obtido pela soma dos três números da coluna.

\section{Gráfico I - Quantidade de citações por categorias e grupos focais}

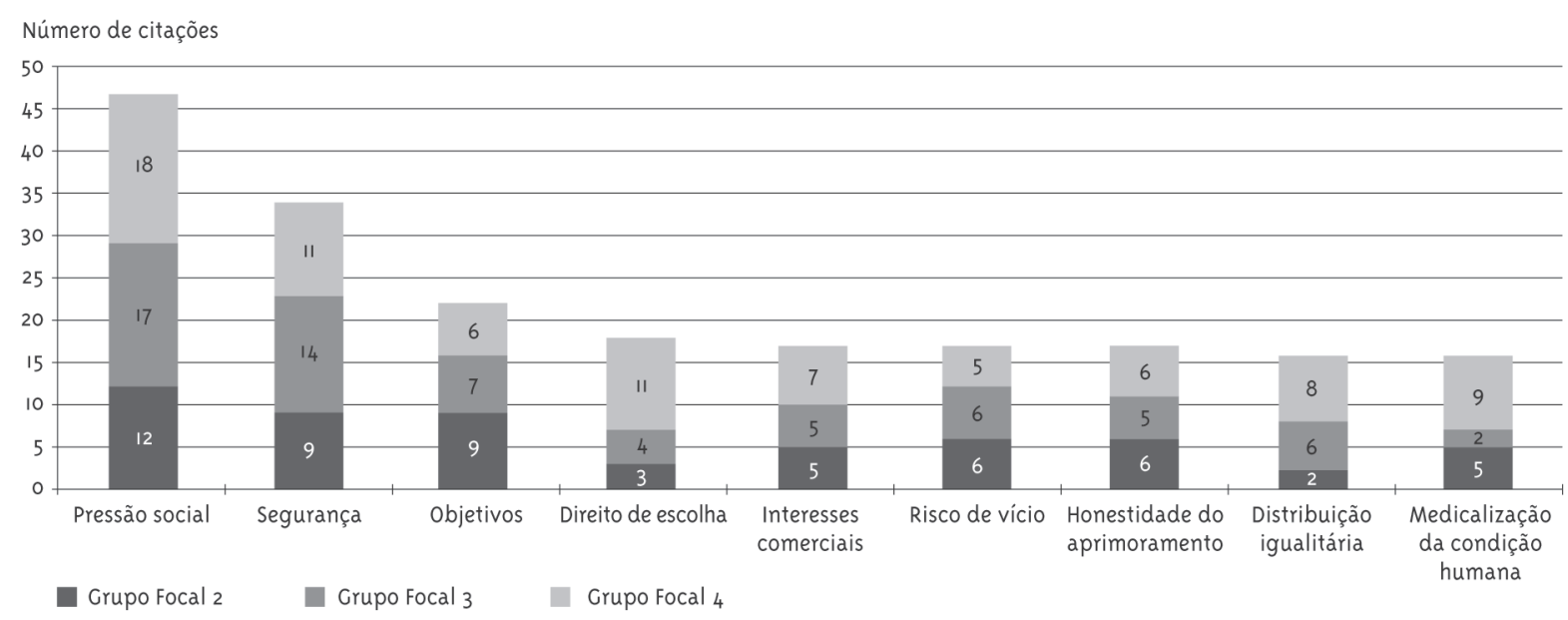

A investigação com os grupos focais mostrou que a maioria dos entrevistados não tinha informação prévia sobre o tema apesar de conhecer a prática do "aprimoramento" com o uso do café e de outros remédios (sem ser o metilfenidato) para facilitar o estudo.

Durante o debate, enquanto as discussões versavam sobre as motivações que levavam uma pessoa a usar medicamentos para otimizar o rendimento acadêmico, a Pressão social para melhorar o desempenho foi a principal categoria utilizada. No encadeamento de ideias associado a essa categoria, surgiu a percepção de que a cobrança social exigia um comportamento sobre-humano e uma postura competitiva, tanto com os outros como consigo 
mesmo. Ainda durante a discussão desse tópico, foi ressaltado que a importância de cumprir a exigência social de excelente performance viria do fato de este ser o principal meio de inserção no grupo, buscando tornar-se o melhor para conseguir realizar os desejos. Tais ideias foram identificadas nos seguintes trechos:

“... a sociedade, o mercado, impõem às pessoas um ritmo [...] sobre-humano, não tem como as pessoas não tomarem [medicamento para aprimoramento cognitivo]. Porque a pressão é muito grande, às vezes ela vê como o único recurso viável para ela ter um desempenho que é cobrado dela”.

"Porque minha nota [caso fosse baixa], com ela, eu não faço mais a pós-graduação que eu quero. Eu acho que há uma olimpíada nesse sentido, e ela não é às vezes só contra o outro, é contra você mesmo."

"Porque você tem um enquadramento social que você deve atender. Então 'neura', essa neurose toda, tipo essa doença toda ela vem mastigada pragente, a gente vai entrando nisso, para uniformizar a coisa, senão você está fora. Se você está fora você não tem o carro que você quer, não tem a casa que você quer, consequentemente, vamos dizer assim, num plano de reino animal, a fêmea vai ficar com o macho mais forte, que é o dominante. No nosso mundo capitalista também vocênãovai ter o que você quer. E rola muita pressão."

Nos três grupos, a Segurança no uso do medicamento foi a segunda categoria mais discutida. Apesar de os participantes não terem informações claras sobre a segurança do fármaco em questão para o neuraprimoramento, eles trouxeram e usaram suas representações sobre a segurança no uso de outros remédios para expressar suas ideias sobre o uso do metilfenidato nessa prática. Alguns entrevistados entenderam que a legalização de um remédio depende de pesquisas que confirmem sua segurança e, por isso, não haveria problemas em usar o metilfenidato para aprimoramento, pois ele já foi aprovado para o tratamento do TDAH. Outros entenderam que o uso de um remédio para fins diferentes do original precisaria de mais pesquisas, pois a nova aplicação ainda não foi investigada. Apesar da divergência na compreensão do que significa segurança de um "novo" uso do medicamento, todos demonstram que essa é uma questão muito importante para a autorização da prática. A preocupação incluiu riscos de dependência e efeitos colaterais que podem atingir o usuário e outras pessoas. Tais ideias foram explicitadas nos seguintes trechos:

“... você não sabe as consequências [do metilfenidato para aprimoramento cognitivol e acha que vai... A gente não sabe se éviciante, se causa dependência, se é se não... Então acha que vai usar uma vez e depois vai melhorar, né? Não vai mais usar, tipo, eu não sei, não tem estudos aprofundados [...] com as consequências, eu não sei, se eu pudesse vir a usar, sabe?".

"Outra coisa que eu queria falar é que não existe só o risco para a pessoa que está tomando, por falta de conhecimento, de quais são as consequências disso. Acho que a pessoa pra perceber, no caso, os médicos, [...] precisam de cuidado. Como que... Será que... Como que o médico que vai estar tomando este medicamento Ipara aprimoramentol vai estar habilitado pra cuidar de uma pessoa, assim? Bem, vai estar consciente de tudo que ele está fazendo? Qual o controle [...] de receitar um medicamento e não dar uma superdosagem? Acho que ele se submete ao perigo, mas também submete as pessoas, que estão ali necessitando do cuidado dele."

Também foi lembrado que a segurança de um fármaco em geral depende de suas interações com outras substâncias e com o estado físico da pessoa. Mesmo assim, tal compreensão não afastou o questionamento sobre o que é segurança de um remédio. Alguns entenderam que saber que o remédio faz mal em determinadas condições é suficiente para afirmar que há uma segurança. Porém, outros compreenderam que conhecer os possíveis riscos não torna o uso do fármaco seguro. Essas ideias estão expressas nos trechos a seguir:

"Só que, aquele lance, quem sofre de problemas de coração não pode tomar Viagra, dependendo do [...] tô tentando estabelecer, [...] tá tomando esse medicamento e aí numa hora, junta com alguma outra coisa, alguma outra coisa que ele fez ou usou, e fez mal! E aí ele vai, entendeu?". 
"Mas eles sabem e eles não se importam com isso. O que que é seguro? Eu te receitar uma coisa que eu sei que você não precisa e eu sei que vai te fazer mal. Essa questão que eu coloco: o que que é seguro? Seguro é eu saber o que vai acontecer comigo se eu tiver, se eu fizer uma overdose? Um uso acima do normal? Ou seguro é eu não sabere [...] morrer sem saber que aquilo que me causou? o que que é seguro? Seguro é ter consciência ou é realmente não ter?"

"Mesma coisa eu te pergunto? O que que é seguro pra você?"

"Pra mim é saber!"

"É exatamente isso? Ou é tomar uma coisa que não é destinada àquilo, você sabe que vai te fazer mal e é seguro porque você sabe?"

Somando todos os grupos focais, a terceira categoria mais citada trata dos Objetivos do aprimoramento cognitivo. Segundo os participantes, os objetivos dessa prática incluem: ampliar capacidades como ficar mais ativo e mais atento; melhorar o desempenho de tarefas e atividades que envolvam habilidades cognitivas; e, finalmente, atender o excesso de expectativas sociais de performance tanto para estar inserido no grupo como também para destacar-se. Quatro exemplos ilustram esses objetivos:

"Ah, vou tomar hoje pra poder ficar mais ativo ou até terminar esse projeto, esse trabalho, estou meio cansado".

"Tomando remédio pra aumentar a sua atenção, porque é exigido dele mais do que ele pode fazer."

“... e se propõe o remédio que vai fazer com que você melhore a sua capacidade de concentração. De atenção, e receber aquelas informações, e vai saber se vai ter uma melhor prova, você vai se igualar."

"Só não sei até quanto isso [uso de medicamento para neuroaprimoramento] é para se manter dentro da massa, ou se destacar desta massa."

Ao falar dos objetivos, os entrevistados afirmaram que a repetição do uso "não médico" do metilfenidato resultaria do sucesso na realização das metas. Essa ideia foi explicitada da seguinte forma:

" $E$ aí de acordo com o que você vai sentindo, os efeitos daquilo [do uso de metilfenidato para melhorar a cognição], você vai chegando onde você está querendo, alcançando as suas metas. Você vai tomando, tomando, e vai chegar um momento em que você não vai conseguir se livrar daquilo".

Durante os debates, o Direito de escolher o neuroaprimoramento farmacológico foi outra categoria que surgiu de forma significativa. Alguns entenderam que as pessoas deveriam ter o direito de decidir pela prática enquanto outros afirmaram que as pessoas não deveriam ter esse direito. Associado a esse tópico, quase todos os entrevistados expressaram preocupação com o risco de surgir uma coerção social, impossibilitando a opção de não usar o fármaco para “aprimoramento". Foi também ressaltado por eles que a propaganda seria uma forma de coerção. Tais ideias ficaram claras nas seguintes falas:

"Vocês acham que a Ritalina ${ }^{\circledR}$ deve estar disponível para esse forma de uso não médico?”.

"Não! [todos]".

"Não por esse motivo até que ela falou, né? O uso deve ser prescrito para pessoas que têm déficit, ou seja, que tenha o diagnóstico de que necessita usar esse medicamento."

“... ela usa aquilo pro bem. Porque pra ela é melhor, porque ela trabalha melhor. $E$ por que não ser assim? Se aquilo é melhor, por que não tomar Ritalina ${ }^{\circledR}$ para chegar ao melhor?”

"Eu acho que o efeito negativo socialmente falando éque ia criar um rebuliço geral, né? As pessoas seriam mais cobradas, e aí ia ficar aquele negócio: 'ah! você não faz [...]'. Os seus limites seriam desafiados, e se você não chegasse num patamar de fazer a quantidade de coisas que te colocam pra fazer, a pessoa ia chegar pra você e falar: 'Ué! Mas você não toma o remédio porque você não quer. Você tem condições de fazer tudo que você é, tudo que te é obrigado a fazer. Você não faz porque vocênão quer. Porque tem a possibilidade de você tomar o remédio, e fazer."” 
“... a indústria farmacêutica fazer propaganda, isso [aprimoramento cognitivo farmacológico] seria disseminado e meio que as pessoas seriam obrigadas a usar."

A influência dos Interesses comerciais da indústria farmacêutica na liberação e incentivo à prática também foi debatido. Nessa categoria, o grupo apresentou certa unanimidade em suas falas. Os quatro pontos mais significativos foram: a possível negligência com a segurança do remédio para aumentar os lucros da empresa; a forte influência da indústria farmacêutica e da publicidade na criação de demanda por um produto; a possibilidade de a comercialização desse produto intensificar ainda mais desigualdades socioeconômicas; e o risco de a publicidade funcionar como uma coerção para o neuroaprimoramento farmacológico. Como pode ser visto a seguir:

“... mesmo sem saber os efeitos [colaterais], a partir do pressuposto de que [o remédio] está disponivel, então ia ter sempre alguém interessado naquilo e a indústria farmacêutica ia se apropriar daquilo...”.

“... a publicidade ia se apropriar disso, e aívocê ia ligar sua TV e ia ver um comercial, num estilo comercial de margarina, falando: 'Tome Ritalina ${ }^{\circledR}$ e faça seu dia durar!', porque você é uma mulher que trabalha das oito às seis, e quando você chega em casa você está cansada pra brincar com seu filho. Então você precisa da Ritalina ${ }^{\circledR}$...”

"Pobre não pode comprar Ritalina ${ }^{\circledR}$ então os pobres continuam sendo burros, e os ricos que têm dinheiro pra comprar Ritalina ${ }^{\circledR}$ vão, cada vez, aprimorar mais as suas capacidades cognitivas e va... essa separação pobre e burro e rico inteligente vai ficar meio marcada. O que hoje não, ainda tem aqueles casos, nem todo mundo que tem dinheiro é inteligente, nem todo pobre é burro. Mas se a capacidade cognitiva for aperfeiçoada por um remédio e se, se esse remédio for caro eu acho que assim essa separação vai ficar mais marcada ainda."

“... a indústria farmacêutica fazer propaganda... isso seria disseminado e meio que as pessoas seriam obrigadas [...] a usar."
Os entrevistados demonstraram que não tinham conhecimentos sobre o Risco de vício do uso "não médico" do metilfenidato. Mesmo assim, todos expressaram preocupações com a possibilidade de dependência psicológica, seja pelo hábito de usar o "facilitador", seja pelo incentivo da indústria farmacêutica. As falas a seguir ilustram essas apreensões:

"Mas tambémé[dependência] psicológica. Porque você está lá, você está com sono, está começando a ficar cansado: 'Ah tenho que terminar de ler duas linhas, se eu não tomar [metilfenidato] eu não vou conseguir, se tomar eu vou conseguir'”.

"Eu acho que com certeza seria muito explorado por indústrias farmacêuticas, que lucram com a venda, né? Então... Independente de quem esteja comprando o interesse évender. Então [...] assim, sei lá, uma [...] dependência larga das pessoas."

Quando foi discutido sobre a Honestidade de usar o neuroaprimoramento farmacológico, surgiram opiniões divergentes. Os diferentes posicionamentos sobre honestidade e desonestidade tiveram sua origem na concepção da vida acadêmica ser ou não competitiva e na existência ou não de uma igualdade de condições anterior ao uso do medicamento. Houve ainda a compreensão de que essa prática é desleal, pois o remédio melhoraria uma capacidade que a pessoa não tem naturalmente. Surgiu também o argumento que alerta sobre a ajuda da droga ser apenas um dos fatores que interfere no desempenho. Alguns trechos dos debates expressam essas questões descritas:

“... um que não tem medo de usar droga, toma Ritalina ${ }^{\circledR}$ e o outro que tem o pai rico paga um professor particular, vai a Paris ver com seus próprios olhos, e também, assim... acho que as pessoas veem assim, mas, eu acho que não éuma corrida, né? Não é uma olimpíada. Uma copa do mundo. A academia, formação não é uma, um esporte que necessite de doping. Esse tipo de coisa, uma busca que todo mundo pode chegar junto no mesmo lugar, né?"

"Então eu acho que se colocar duas pessoas com patamar igual, dois indivíduos iguais, e aí um deles faz uso, seria então: desigual contra o outro que não faz uso. Agora quando nós temos 
indivíduos diferentes, distintos, um tem maior capacidade, énatural para ele... Beleza! [...] quimicamente, então eu estou buscando um alcance... uma 'similitude'. Até aí não. Nós [grupo social] não somos compostos de indivíduos totalmente iguais. Às vezes alguém tem mais instrução, desde pequeno, e aí um outro cai num meio universitário, e são uma gama de informações e ele está tentando correr atrás de um tempo perdido que foi pra ele. $E$ aí ele está tendo uma certa dificuldade de compreensão de coisas que o outro que ia pra Paris nas férias, e tudo, tem uma gama de coisas que ele já via antes, no cotidiano deles. Já lia artigos, o pai dele era médico. Ele estava acompanhando aquelas informações. O outro vai ter maior dificuldade, precisa de um estímulo."

“... o meu corpo não tem capacidade de produzir uma substância então eu vou ingerir [o remédio]. Uma outra pessoa ela não tem também essa capacidade, de produzir [a substância]. Então, qualquer artifício, não são propriamente meus, passam a ser [...] naturalmente meus, para poder conseguir alguma coisa. Então seria desleal."

“... o cientista 1 vai ser melhor que o cientista 2 porque ele usou uma droga pra se concentrar?! [risos] Dentro desses [...] que ele esteja controlando a concentração, é apenas um fator deles."

Quando os grupos conversaram sobre Distribuição igualitária do metilfenidato também surgiram divergências. Alguns participantes afirmaram que o aprimoramento cognitivo farmacológico não deve estar disponível para todos. Contudo, a maioria dos entrevistados ponderou que uso de um "aprimorador cognitivo" poderia ser liberado caso fossem garantidas algumas "condições" como: a segurança no uso do remédio, a ampliação da consciência do público; e a real disponibilidade do fármaco para todos. Tais ideias podem ser lidas nos trechos a seguir:

“[A Ritalina $\left.{ }^{\circledR}\right]$ deve estar disponível para essa forma de uso "não médico?".

"Não! [todos] Não!"

"[Sobre a Ritalina ${ }^{\circledR}$ estar disponível para todos] Eu acho que poderia ser mais [...] pesquisas mais elaboradas em relação a contra-indicações, e se conseguisse determinar o que acontece com o uso da Ritalina ${ }^{\circledR}$, poderia ser sim, aberto.”

"Eu acho que não, porque, por enquanto não, porque as pessoas estão meio descontroladas [...] $e$ é muito da consciência, assim, quando tiver uma conscientização melhor é que poderia.”

"Eu quero saber o seguinte: quem vai usar [o metilfenidato para aprimoramento] vai ser um aluno da PUC? Vai ser alguém com dinheiro, ou da UERJ, alguém com dinheiro? Aí se cria então uma desigualdade. Se vai colocar vinte comprimidos na cartela por cinco reais, qualquer estudante pode comprar, não faz mal pra ninguém, eu vou tomar três por dia pra poder ler um [...] desse tamanho."

Quanto à categoria Medicalização da condição humana, houve certa unanimidade nas opiniões dos entrevistados. Segundo eles, a possibilidade de usar um remédio (metilfenidato) para otimizar a performance cognitiva é uma expressão da atual tendência de pensar os problemas e limites pessoais como condições médicas que podem ser corrigidas por um fármaco. Os argumentos associados a esse tópico incluíram: o excesso de prescrição médica; a banalização no uso de remédios em decorrência da automedicação e da ideia de que o uso de fármaco só faz bem; a grande valorização das descobertas científicas e a busca por medicamentos para melhorar as capacidades que faltam às pessoas. Esses quatro argumentos podem ser acompanhados nos trechos que seguem:

"Por exemplo, quando uma mãe chega no médico, fala pro médico: 'Olha, meu filho não consegue... não está acompanhando a turma, não está fazendo os exercícios'. O primeiro diagnóstico: 'Ah! Déficit de atenção... toma Ritalina ${ }^{\circledR}$ '. Mas na verdade você tem que analisar se aquela criança está no momento dela. Acho que tudo empurra, tudo vai te levar ao uso de medicamento".

"Porque você está acostumado a ter uma dor de cabeça e se automedicar. Então pra você não é problema nenhum tomar um medicamento que é controlado que vai mexer no seu sistema nervoso central. $\tilde{\varepsilon}$ como se não tivesse tanta diferença, porque já está enraizado."

" $E$ eu acho que tem que se repensar essa história 
de medicação. Eu acho que tem que ser feita uma avaliação em relação ao uso de medicamentos de uma forma geral. Porque eu acho que isso fica um pouco banalizado. [...] acha que medicação não faz mal. Só melhora, só ajuda. Então eu acho que de uma forma geral todo medicamento deve ser usado de forma relativa, terapêutica."

“... não é nem falar que seja uma questão de moda, mas é uma questão de [...] o medicamento foi descoberto, foi comprovado por pesquisa, está em alta, que é legal tentar, e aí de repente eu já passei por isso por uma terapia que tinha falado 'eu acho que você tem TDAH'. Eu só tinha falado: "Oi o meu nome éx". É...já está querendo me prescrever. Eu acho, então, que pela prescrição inadequada também, em função desse furor, científico. Da descoberta do medicamento."

"A pessoa aí, no caso, estaria procurando no remédio [metilfenidato] uma capacidade que ele não tem naturalmente. Uma atenção além do seu normal, além do seu natural, para conseguir ter desempenhos melhores."

\section{Discussão}

Os grupos focais revelaram que o Aprimoramento Cognitivo Farmacológico é um tema polêmico, pois envolve importantes aspectos sociais. A questão mais citada pelos entrevistados foi a pressão social para ter um excelente desempenho. Realizar muito bem um grande número de tarefas em pouco tempo exige das pessoas um comportamento além dos próprios limites. Essa exigência é aumentada porque a performance profissional/cognitiva foi considerada a principal fonte de reconhecimento social justificando, assim, o grande esforço para superar a si mesmo e ser melhor que os outros.

O desejo de garantir sua inserção no grupo buscando ser o melhor confirma o argumento de Ehrenberg (1991) que relaciona a competição e o consumismo com a responsabilidade individual de inventar a si mesmo. Segundo o autor, a identidade passa a ser demonstrada por meio de realizações pessoais. $\mathrm{O}$ alto valor do desempenho na construção de identidade e reconhecimento social transforma a busca pela ótima performance em uma "exigência imediata".
O imperativo do excelente desempenho parece favorecer o entendimento dos problemas e limites pessoais como condições patológicas que devem ser curadas e medicadas. A atual tendência de medicalização da condição humana, criticada pelos estudantes, foi identificada por eles como um fator que contribui para o uso "não médico" dos fármacos.

Durante os grupos focais, surgiram questionamentos sobre a possibilidade de o uso "não médico" do fármaco favorecer a dependência psicológica. Afinal, os estudantes entenderam que quanto maior o número de metas alcançadas com o uso do medicamento, maior o reforço da crença de que a realização dos objetivos dependeria do consumo do remédio.

Além da apreensão com o risco da dependência psicológica, todos demonstraram que a garantia da segurança no uso do fármaco como "aprimorador cognitivo" é uma condição fundamental para sua aceitação. Contudo, surgiram divergências para definir os critérios de tal avaliação. As principais questões incluíram a existência ou não da necessidade de estudos mais profundos sobre esse "novo" uso e se a identificação e divulgação dos riscos do medicamento são suficientes, ou não, para afirmar que seu uso é seguro.

Segundo os grupos, a falta de cuidado com a segurança da medicação seria consequência dos interesses comerciais da indústria farmacêutica. Para manter seus lucros, a indústria não divulgaria informações sobre os efeitos danosos de seus produtos. Eles também afirmaram que a indústria farmacêutica, por meio dos informes publicitários, valorizaria os benefícios dos remédios ampliando a necessidade de consumo. Por esse motivo, os entrevistados mostraram-se apreensivos com a publicidade, pois esta poderia funcionar como uma coerção para o uso do fármaco como "aprimorador cognitivo".

O risco de uma coerção (direta ou indireta) foi uma importante preocupação entre os estudantes. A justificativa para tal apreensão parece estar associada ao fato de a coação ferir o direito de escolha (autonomia) dos indivíduos. Nas sociedades ocidentais, tal direito é considerado um princípio fundamental que deve ser garantido a todos.

Outro problema de cunho social levantado pelos entrevistados foi o risco de o metilfenidato ser caro 
e de difícil acesso às pessoas. Apesar de alguns integrantes terem entendido que diferenças socioeconômicas dos estudantes poderiam ser amenizadas com a prática do neuroaprimoramento farmacológico, quase todos entenderam que um acesso desigual ao medicamento poderia intensificar as diferenças sociais.

Além disso, nos grupos surgiram opiniões sobre este método ser honesto ou desonesto. Os diferentes posicionamentos estavam baseados no entendimento de o meio ser competitivo ou não. Se o "aprimorador cogntivo" for usado em um ambiente competitivo, ele é desonesto. Caso contrário, ele é um método honesto e leal.

Dessa forma, é possível pensar que a preocupação com a coerção e a honestidade do método está relacionada com o ideal social de garantir igualdade de condições entre os cidadãos. A igualdade é outro aspecto tido como fundamental nas sociedades liberais democráticas que adotaram os direitos humanos como referência para suas condutas e práticas.

Apesar de não ser possível estender o resultado da investigação com grupos focais para todo o universo pesquisado, os dados mostram que o aprimoramento cognitivo farmacológico é um tema relevante, suscitando muitas questões entre os entrevistados. Além de problemas mais objetivos como a regulamentação e segurança da prática, o neuroaprimoramento levanta questionamentos sobre os direitos de livre escolha, igualdade de condições e justiça social em uma sociedade com alta exigência social de performance profissional e cognitiva.

\section{Considerações Finais}

A proposta do presente trabalho foi analisar as representações sociais do aprimoramento cognitivo farmacológico. Como um primeiro estudo exploratório, sem a pretensão de esgotar o tema, a investigação revelou que, entre os universitários entrevistados, não houve consenso sobre a aceitação da prática. Alguns participantes entenderam que o neuroaprimoramento farmacológico deve ser tratado como o uso de drogas ilícitas, devendo ser proibido. Outros foram a favor da legalização da prática com a condição de que sejam tomados cuidados com a segurança no uso do medicamento e com as consequências sociais aí envolvidas. Houve também a compreensão de que as pessoas deveriam ser livres para escolher usar (ou não) fármacos para melhorar o rendimento cognitivo.

A análise das questões levantadas nos grupos focais parece indicar que o aprimoramento cognitivo farmacológico não fere a moralidade dos entrevistados. Os grupos demonstram uma maior tolerância às práticas que alteram a neurobiologia a favor do ideal social de melhoria da performance das pessoas. A principal preocupação com a prática está relacionada ao risco de esta intensificar injustiças e desigualdades entre as pessoas em sociedades que já apresentam significativas diferenças sociais.

É inegável a contribuição que os avanços biotecnológicos trazem para o bem-estar da humanidade. Mas esses progressos precisam ser analisados e discutidos. Além da segurança das novas intervenções, faz-se necessário buscar compreender qual o sentido social das novas práticas na construção e manutenção da subjetividade. Dessa forma, a investigação das representações sociais do neuroaprimoramento farmacológico favorece uma melhor compreensão das questões aí envolvidas ajudando a nortear ações em Saúde Coletiva.

\section{Referências}

BUSH, S. Neurocognitive enhancement: ethical considerations for an emerging subspecialty. Applied Neuropsychology, London, v. 13, n. 2, p. 125-136, 2006.

BUTCHER, J. Cognitive enhancement raises ethical concerns. Lancet, New York, v. 362, n. 9378, p. 132-133, 2003 .

CAPLAN, A. Is better best? Scientific American, New York, v. 289, n. 3, p. 104-105, 2003.

CAPLAN, A.; ELLIOTT, C. Is it ethical to use enhancement technologies to make us better than well? PLoS Med, San Francisco, v. 3, n. 1, p. 52, 2004.

CARLINI-COTRIM, B. Potencialidades da técnica qualitativa grupo focal em investigações sobre abuso de substâncias. Revista de Saúde Pública, São Paulo, v. 3o, n. 3, p. 285-293, 1996. 
CHATTERJEE, A. Cosmetic neurology: the controversy over enhancing movement, mentation, and mood. Neurology, St. Paul, v. 63, n. 6, p. 968-974, 2004.

CHAU, V. Popping pills to study: neuroethics in education. Stanford Journal of Neuroscience, Stanford, v. 1, n. 1, p. 18-20, 2007.

DEES, R. Slippery slopes, wonder drugs, and cosmetic neurology. Neurology, St. Paul, v. 63, p. 951-952, 2004.

DILLER, L. The run on Ritalin: attention deficit disorder and stimulant treatment in the 199os.

The Hastings Center Report, New York, v. 26, n. 2, p. 12-18, 1996.

EHRENBERG, A. Le culte de la performance. Paris: Hachette Littératures, 1991.

ELLIOTT, C. American bioscience meets the American dream. The American Prospect, Washington, DC, v. 14, p. 38-42, 2003.

ELLIOTT, R. et al. Effects of methylphenidate on spatial working memory and planning in healthy young adults. Psychopharmacology, Heidelberg, v. 131, n. 2, p. 196-206, 1997.

FARAH, M. J. et al. Neurocognitive enhancement: what can we do and what should we do? Nature Reviews Neuroscience, London, v. 5, p. 421-425, 2004 .

FENTON, A. Buddhism and neuroethics: the ethics of pharmaceutical cognitive enhancement. Developing World Bioethics, Kingston, v. 9, n. 2, p. 47-97, 2009.

GREELY, H. et al. Towards responsible use of cognitive-enhancing drugs by the healthy. Nature, London, v. 456, p. 702-705, 2008.

GONDIM, S. M. G. Perfil profissional e mercado de trabalho: relação com a formação acadêmica pela perspectiva de estudantes universitários. Estudos de Psicologia, Natal, v. 7, n. 2, p. 299-309, 2002.

HALL, K. et al. Illicit use of prescribed stimulant medication among college students. Journal of American College Health, Linthicum, v. 53, n. 4, p. 167-174, 2005.
HALL, W. Feeling 'better than well': can our experiences with psychoactive drugs help us to meet the challenges of novel neuroenhancement methods? EMBO Reports, Heidelberg, v. 5, n. 12, p. 1105-1109, 2004.

HYMAN, S. Improving our brains? Biosocieties, Cambridge, v. 1, n. 1, p. 103-111, 2006.

KASS, L. Beyond therapy: biotechnology and the pursuit of happiness. New York: Harper Collins; 2003.

KRUEGER, R. A. Focus groups: a practical guide for applied research. Newbury Park: Sage, 1988.

LOW, K. G.; GENDASZEK, A. E. Illicit use of psychostimulants among college students: a preliminary study. Psychology, Health and Medicine, Oxfordshire, v. 7, n. 3, p. 283-287, 2002.

MAGUIRE JR, G. Q.; MCGEE, E. M. Implantable brain chips?: time for debate. Hastings Center Report, New York, v. 29, n. 1, p. 7-13, 1999.

MAHER, B. Poll results: look who's dopping. Nature, London, v. 452, p. 674-675, 2008.

MAURON, A. Renovating the house of being: genomes, souls, and selves. Annals of the New York Academy of Sciences, New York, v. 1001, n. 1, p. 240-251, 2003.

MEHTA, M. A. et al. Methylphenidate enhances working memory by modulating discrete frontal and parietal lobe regions in the human brain. The Journal of Neuroscience, Washington, DC, v. 20, n. 6, p. 1-6, 2002.

MINAYO, M. C. O desafio do conhecimento: pesquisa qualitativa em saúde. Rio de Janeiro: Abrasco, 1992.

MORGAN, D. Focus groups as qualitative research. London: Sage, 1997.

NIDA - NATIONAL INSTITUTE ON DRUG ABUSE. Prescription drugs: abuse and addiction. Bethesda, 2005. (Research Report Series)

NOVARTIS BIOCIÊNCIAS SA. Ritalina: cloridrato de metilfenidato. Brasília, DF: Anvisa, 2007. Bula. Disponível em : <http://www4.anvisa.gov.br/base/ visadoc/BM/BM\%5B26162-1-o\%5D.PDF>. Acesso em: 12 maio 2011. 
RACINE, E.; FORLINI, C. Cognitive enhancement, lifestyle choice or misuse of prescription drugs: ethics blind spots in current debates. Neuroethics, Dordrecht, v. 3, n. 1, p. 1- 4, 2008.

SAHAKIAN, B.; MOREIN-ZAMIR, S. Professor's little helper. Nature, London, v. 450, n. 20, p. 11571159, 2007.

SENTENTIA, W. Neuroethical considerations: cognitive liberty and converging technologies for improving human cognition. Annals of the New York Academy of Sciences. New York, v. 1013, p. 221-228, 2004.

SINGH, I.; ROSE, N. Neuro-forum: an introduction. Biosocieties, Cambridge, v. 1, n. 1, p. 97-102, 2006.

SOLANTO, M. Neuropsychopharmacological mechanisms of stimulant drug action in attention-deficit hyperactivity disorder: a review and integration. Behavioural Brain Research, Dusseldorf, v. 94, p. 127-152. 1998.

SZOBOT, C. M. et al. Neuroimagem no transtorno de déficit de atenção/hiperatividade. Revista Brasileira de Psiquiatria, São Paulo, v. 23, n. 1, p. 32-35, 2001.

TETER, C. et al. Prevalence and motives for illicit use of prescription stimulants in an under. The Journal of American College Health, Linthicum, v. 53, n. 6, p. 253-262, 2005.
TETER, C. et al. Illicit use of specific prescription stimulants among college students: prevalence, motives, and routes of administration.

Pharmacotherapy, Boston, v. 26, n. 10, p.1501-1510, 2006.

THE MTA COOPERATIVE GROUP. A 14-mongh randomized clinical trial of treatment strategies for Attention-Deficit/Hyperactivity Disorder. Archives of General Psychiatry, Chicago, v. 56, p. 1073-1086, 1999.

TURNER, D.; SAHAKIAN, B. Neuroethics of cognitive enhancement. Biosocieties, Cambridge, v. 1, n. 1, p. 113-123, 2006.

UN - UNITED NATIONS. Convention on Psychotropic Substances, 1971. Vienna, 1971. Disponível em: <http://www.incb.org/pdf/e/conv/ convention_1971_en.pdf >. Acesso em: 2 mar. 2009.

WHITE, P. et al. Stimulant medication use, misuse, and abuse in an undergraduate and graduate. The Journal of American College Health, Linthicum, v. 54, n. 5, p. 261-268, 2006.

WOLPE, P. Treatment, enhancement, and the ethics of neurotherapeutics. Brain and Cognition, St. Catharines, v. 5o, n. 3, p. 387-395, 2002. 